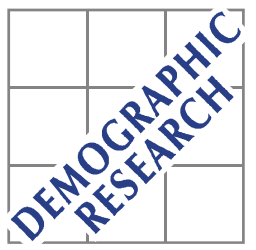

Demographic Research a free, expedited, online journal

of peer-reviewed research and commentary in the population sciences published by the Max Planck Institute for Demographic Research

Konrad-Zuse Str. 1, D-18057 Rostock · GERMANY

www.demographic-research.org

DEMOGRAPHIC RESEARCH

VOLUME 19, ARTICLE 48, PAGES 1693-1726

PUBLISHED 23 SEPTEMBER 2008

http://www.demographic-research.org/Volumes/Vol19/48/

DOI: $10.4054 /$ DemRes.2008.19.48

Research Article

\title{
The influence of parents on cohabitation in Italy: Insights from two regional contexts
}

\section{Christin Schröder}

\section{(C) 2008 Schröder.}

This open-access work is published under the terms of the Creative Commons Attribution NonCommercial License 2.0 Germany, which permits use, reproduction \& distribution in any medium for non-commercial purposes, provided the original author(s) and source are given credit.

See http:// creativecommons.org/licenses/by-nc/2.0/de/ 


\section{Table of Contents}

1 Introduction 1694

2 Data and methods $\quad 1697$

3 Categories of analysis 1701

$4 \quad$ Results 1704

4.1 Striving towards conformity 1705

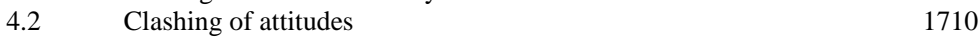

$\begin{array}{lll}4.3 & \text { Benefiting from parental support } & 1715\end{array}$

5 Summary 1718

6 Discussion 1721

$7 \quad$ Acknowledgements 1722

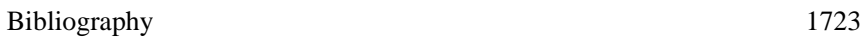




\title{
The influence of parents on cohabitation in Italy: Insights from two regional contexts
}

\author{
Christin Schröder ${ }^{1}$
}

\begin{abstract}
In view of the demographic changes that affect all European countries, the diffusion of new living arrangements such as non-marital cohabitation is particularly interesting. In this article we concentrate on Italy, a country that is characterized by a low pace in the diffusion of cohabitation. Earlier studies found statistical evidence of the impact of parents' characteristics on young adults' decisions for cohabitation. However, there is only limited empirical knowledge about the actual mechanism through which parents influence the choices of their children. We employ qualitative research methods and focus on two regional contexts in order to analyze if and how parents intervene in the choices of young adults.
\end{abstract}

\footnotetext{
${ }^{1}$ Ph.D. Student, Max Planck Institute for Demographic Research, Konrad-Zuse Strasse 1, 18057 Rostock, Germany. E-Mail: schroeder@demogr.mpg.de.
} 


\section{Introduction}

In Italy, union and family formation are characterized by several peculiarities, making the country stand out as far as demographic development in Europe is concerned: Italy witnesses both strong postponement of events related to the transition to adulthood (such as leaving home, forming a union and becoming a parent) and high synchronization between leaving the parental home and entry into marriage (Billari 2004; Billari et al. 2000; Ongaro 2004). Despite the unbroken importance of marital union, marriage rates started to decrease from the mid-1970s onwards. The drop, however, was not compensated by a rise in the incidence of alternative living arrangements, such as cohabitation. Rather, it created a vacuum as a large proportion of young adults continue to stay with their family of origin rather than form a union (Kiernan 1999; De Sandre et al. 1997).

Thus, whereas most European countries have witnessed to some degree strong increases in informal unions over recent decades, the same is not true for Italy. By 2000-01, the highest levels of cohabitation were found in the Northern European countries of Sweden, Denmark, and Finland as well as in France. Austria, the Netherlands, Germany, and Great Britain were in the middle group, whereas Southern European countries showed the lowest cohabitation rates (see Figure 1). Although cohabitation figures started to rise in Italy too, the country continues to remain at the low end of the scale. Moreover, Italy is shaped by a high degree of regional heterogeneity. In 2001, 3.6\% of all Italian couples were living in cohabitation. In the northern regions, especially in Valle D'Aosta and Emilia-Romagna, the proportion was between 5\% and 8\%. In Southern Italy we find figures below 2\% (ISTAT 2001). 
Figure 1: Percentage of cohabitation among adults aged 25-34, 2000-01

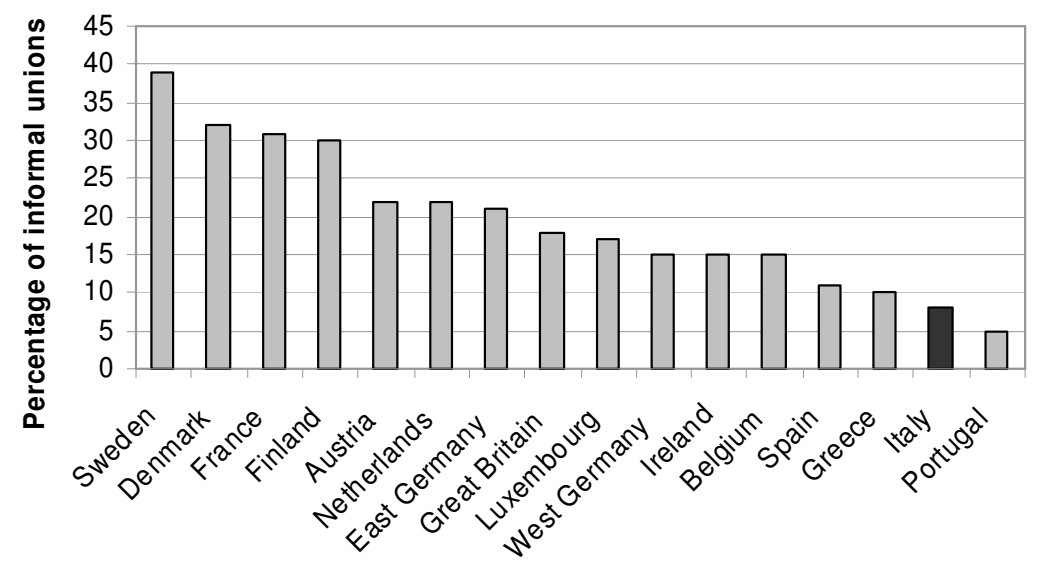

Source: Kiernan 2004 (based on Eurobarometer data of 2000-01).

Previous research focused mainly on the diffusion aspects of cohabitation in Italy, paying almost no attention to the mechanisms responsible for the hesitant development of informal unions in the country. In general, it is argued that economic dependence on the family, the rigid structure of the housing market, high youth unemployment rates, and traditionally strong family ties hamper the formation of informal unions (Ferrera 1996; Holdsworth and Irazoqui Solda 2002; Bernardi and Nazio 2005; Reher 1998; Rosina and Fraboni 2004; Di Giulio and Rosina 2007).

Since there is only limited knowledge about the actual mechanism through which parents influence the choices of their children, we are interested in the question of how - if at all - parents intervene in the choices their children make about entering cohabitation and whether young adults are indeed hampered by their family when it comes to non-marital union formation.

Rosina and Fraboni (2004) claim that a relationship exists between strong family ties and the development of cohabitation in Italy. Since parents are economically and emotionally deeply involved in the lives of their adult children, they consider the success (and failure) of their children in various aspects of life as a consequence of their own far-sighted family strategy. Since parents tend to discourage their offspring from behaving in a way that is socially disregarded (such as cohabitation), their adult children have to rely on prevailing traditions, norms, and values when making choices. Young adults who nevertheless decide for cohabitation may also be 'punished' in that 
they receive less generous help (Di Giulio and Rosina 2004, 2007; Holdsworth and Irazoqui Solda 2002). Rosina and Fraboni (2004) argue that adults may only decide to enter a new living arrangement if their family accepts their choice. These authors found this to apply in particular to families in Northern Italy that have highly educated fathers. In this respect, the father's level of education degree influences the level of openness towards modern living arrangements.

However, in our analysis at the national level ${ }^{2}$ we discovered that the mother's education - also relative to the father's degree - has an even stronger positive impact on their daughter's entry into cohabitation. We believe that mothers with a higher educational degree relative to that of the father have reached a higher level of emancipation and a higher level of decision-making autonomy than their counterparts of lower education relative to that of the father. Consequently, one may assume that these mothers tend to have rather open-minded attitudes towards any modern living arrangements of their daughters. We suppose that these mothers either use their autonomy to provide greater emotional support when their daughters enter cohabitation (against the wish of the father), or that they transmit modern values and attitudes to their daughter right from the start (Schröder 2006). In fact, other studies found evidence that perceived and actual maternal attitudes on cohabitation impacted union formation intentions of young adults in Italy: Young adults showed a higher inclination to enter an informal union if they perceived their mothers to have favorable attitudes towards cohabitation. This effect was even stronger if mothers actually declared that they had these attitudes (Billari and Rosina 2005).

Clearly, employing statistical methods alone does not allow investigating the real mechanisms that guide this process. Therefore we have chosen to work with qualitative research methods. Qualitative methods promise deeper insights on the influence parents have on cohabitation in Italy, including these issues: How - if at all - do parents influence their adult children's choice for cohabitation? Specifically, how do young adults perceive the attitudes their parents have on cohabitation? What kind of importance does the opinion of parents have? How far do economic and non-economic interdependencies influence the decision for cohabitation? How do parents and children communicate about cohabitation? What is the parental reaction to a cohabitation? How does the relation between parents and adult children change after entry into an informal union? To sum up, our study contributes to answering the question, "To what extent does family influence the diffusion of cohabitation in Italy?"

${ }^{2}$ Event history analysis using the 'Indagine longitudinale sulle famiglie italiane' (ILFI) of 1997 and 1999 (Schröder 2006). 


\section{Data and method}

Since we focus on decision-making with regard to an informal union and the mechanisms that guide this process, we have used methods that permit an extensive consideration of "cohabitation" in everyday life - methods that identify the meanings of cohabitation and marriage, and the underlying norms and expectations of and motivations behind personal behavior. Therefore, we conducted a qualitative analysis that allows for a deeper understanding of the social phenomenon (Silverman 2001). As indicated above, previous studies on informal unions in Italy mainly have focused on the diffusion aspect and less on the mechanisms behind the hesitant development of cohabitation. Using quantitative research methods, existing studies fail to capture the motivations behind informal union formation in Italy. In addition, quantitative studies are problematic, as representative studies on Italy have only low numbers of cohabiting unions owing to the rare coincidence of such unions.

The cities selected for our study are Bologna and Cagliari. Bologna is the capital city of the Northern Italian region of Emilia-Romagna. This region is very interesting since the proportion of informal unions rose from 2.3\% of all couples in 1991 to $7.6 \%$ in 2001 (Sabbadini 1997; ISTAT 2001). Thus, Bologna - traditionally governed by liberal left-wing parties - represents a particular regional context with respect to cohabitation: The area witnesses a stronger increase in informal unions than do other Northern Italian regions - this applies not only to the cities, but also to the countryside (author's calculations based on Sabbadini 1997 using census data of 1991 and ISTAT 2001).

Cagliari, on the other hand, is the capital city of the island of Sardinia. Between 1991 and 2001 the share of informal unions in the region doubled from $1.1 \%$ of all couples to 2.4\% (Sabbadini 1997; ISTAT 2001). Sardinia also represents a distinct regional context: Among the southern Italian regions, it displays the highest percentage of informal unions. In general, cohabitation in southern Italy is characteristic for older persons who decide against marriage in order to keep their widow's pension. Only in Sardinia do we find a higher extent of the 'innovative' kind of cohabitation - that is, cohabitation of younger people - in which we are interested (Sabbadini 1997). Figure 2 shows the regional heterogeneity of informal unions in Italy. 
Figure 2: $\quad$ Percentage of informal unions by region, Italy 1991 and 2001

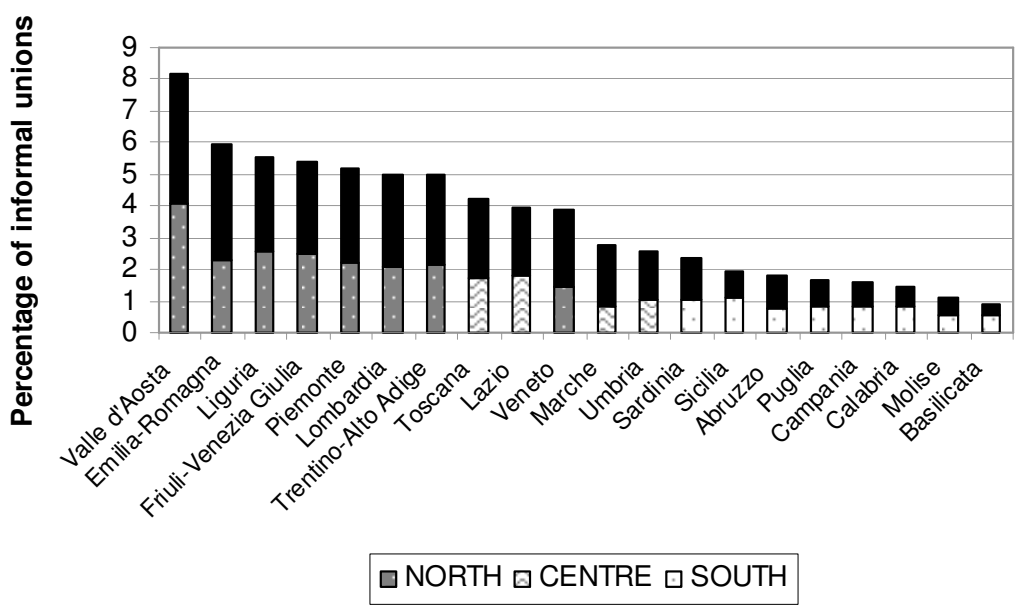

Note: Patterned bars display the percentage of informal unions in 1991; black bars display the further increase up to 2001. Source: (Sabbadini 1997 using census data of 1991) and (ISTAT 2001)

Between May 2005 and May 2006 we conducted 56 semi-structured in-depth interviews (28 interviews in each of the two cities) with cohabiting women, women who married after previous cohabitation, and women with and without children. The Bologna interviewees were identified through register data and were contacted first by phone and then by mail. Furthermore, we used the 'snowball method' to complete our sample. For Cagliari, we used the snowball method only and started with contact persons at social and information services. We intended to interview women aged between 25 and 40, and most women in our final sample are from this age group.

The final data set for Bologna has information on 17 cohabiting women (two of them mothers) and eleven married women (three of them childless). From these, 15 women were born and raised in Bologna, six in the region of Emilia-Romagna, three came from other northern regions to the city, and four came from the South. They mainly moved to Bologna because of their studies and at the time of the interview they had been living there already for many years. For Cagliari, the final data set consists of information on 16 cohabiting women (five of them mothers) and on eleven married women (six of them childless). Additionally we interviewed one single woman who intended to enter cohabitation within the next six months. Fifteen of the Cagliari women were born and raised in Cagliari, nine in Sardinia, two came from Northern Italian regions to the city, and one came from the South. The main reason for moving was the intention to study in Cagliari. Particularly those who came from the Italian 
mainland moved to Cagliari because of their partner. Although we did not sample for education, most of the interviewees in Bologna and Cagliari had a very high educational level as they had completed university education. This is not surprising, since several studies have provided evidence that in Italy higher educated adults are especially prone to enter cohabitation (Sabbadini 1997; Rosina and Fraboni 2004). As to employment, there were many white collar workers in both samples, including several working in the public sector. In Bologna, two interviewees were still students. And in both cities we have women who come from the medical, teaching, or photography professions (see Table 1 for a more detailed description of the sample).

Since we interviewed only women who experience(d) cohabitation, we have no data on women who desired or intended to cohabit, but nevertheless did not enter informal union. We thus cannot investigate why women made a decision against this choice or which factors drove such decision. Furthermore, we cannot provide evidence on women who did not take into consideration the possibility of entering a cohabiting union - maybe because it never seemed to be an option for them. However, as we interviewed also women who decided for marriage after cohabitation, we were able to analyze the reasons and motivations that drove the choice to enter a conjugal union after having lived in an informal union. 
Schröder: The influence of parents on cohabitation in Italy

Table 1: Description of the Bologna and Cagliari Samples

\begin{tabular}{|c|c|c|c|}
\hline & & Bologna & Cagliari \\
\hline & Cohabiting and childless & 15 & 11 (+ 1 Single) \\
\hline \multirow[t]{4}{*}{ Marital status } & Cohabiting and mother & 2 & 5 \\
\hline & Married and childless & 3 & 6 \\
\hline & Married and mother & 8 & 5 \\
\hline & 20-27 Years & 3 & 2 \\
\hline \multirow[t]{4}{*}{ Age by age groups } & 28-35 Years & 12 & 8 \\
\hline & 36-42 Years & 11 & 14 \\
\hline & 43 Years and older & 2 & 4 \\
\hline & Median & 35.0 & 37.5 \\
\hline \multirow[t]{3}{*}{ Median age at ... } & entry into the relationship & 27 & 26 \\
\hline & entry into cohabitation & 28 & 31 \\
\hline & entry into marriage & 31 & 32 \\
\hline \multirow[t]{3}{*}{$\begin{array}{l}\text { Median time spent } \\
\text { in cohabitation } . . .\end{array}$} & $\begin{array}{l}\text { until the time of the } \\
\text { interview (for those } \\
\text { cohabiting) }\end{array}$ & 4 Years & 4.5 Years \\
\hline & $\begin{array}{l}\text { until entry into marriage (for } \\
\text { those having married) }\end{array}$ & 2 Years & 3 Years \\
\hline & Same city & 15 & 15 \\
\hline \multirow[t]{4}{*}{ Region of birth } & Same region & 6 & 10 \\
\hline & North/Center & 3 & 2 \\
\hline & South & 4 & 1 \\
\hline & Lower Secondary & 2 & 1 \\
\hline \multirow[t]{2}{*}{ Educational level } & Higher Secondary & 4 & 5 \\
\hline & University Degree & 22 & 22 \\
\hline
\end{tabular}


The interviews were based on an interview guideline that covered several major topics, such as the motivation behind and decision to cohabit (and marry), as well as economic conditions, past and present family relations, economic and non-economic support, and the families' reactions to cohabitation (especially the parents' reactions). Following the interview, the respondents answered a short questionnaire on their sociodemographic characteristics. Most interviews were about 50 to 60 minutes long.

The interviews were conducted in Italian. The interviewer was of German nationality, a characteristic which possibly had some effect on the respondents' answers. Some interviewees might have trusted a 'stranger' less than someone of their own nationality and thus might have shown some reservations in sharing all of their thoughts on the questions asked. On the other hand, interviewees might have had more trust in the interviewer exactly because of this fact: Some people tend to be more talkative when in discussion with a completely unknown person than with people who live in the same city or region. In addition, the interviews greatly benefited from asking the women to elaborate on what they said, as the interviewer played on the fact that she was not from Italy, thus implying that she knew less about the socio-cultural context than they do.

The interviews were recorded and transcribed. This enabled us to go back to the data several times and to code the material. The coding and categorizing of the interviews is based on grounded theory, a procedure developed by Glaser and Strauss (1967) to analyze qualitative data. Furthermore, we used memos as an intermediate step between coding and analyzing (Charmaz 2000).

The analysis looks primarily for the impact of factors such as parental attitudes, pressure, and economic and non-economic support, etc. We also investigate the way in which and the mechanisms through which parents and adult children talk and negotiate about the children's entry into cohabitation and the parental reaction to the couple's desire to cohabit.

In Section 3, we describe the categories used for the analysis of parental influence in both settings. Section 4 deals with the strategies used among women when entering cohabitation.

\section{Categories of analysis}

We start our analysis with by placing the interviewees into categories following the 'theory of reasoned action' by Ajzen and Fishbein (1980). This theory offers a good starting point for understanding parental influence on cohabitation in Italy. These authors argue that a person will usually act in accordance with her or his intention. In their view, a person's intention is a result of two basic determinants: one personal, the 
other reflecting social influence. Whereas the personal factor is affected by the individual's evaluation of performing the behavior (attitude towards the behavior), the social factor results from the individual's perception of the social pressure to perform or not perform a certain behavior and his or her motivation to comply with this wish (subjective norm). If a person's behavior is blocked by a certain conflict between both determinants, the individual will act according to the relative importance of each.

In order to capture both the personal and social determinants in regard to entry into cohabitation (and/or marriage), we employ a diagram with two dimensions. The first dimension refers to the individual's perception of cohabitation. Cohabitation might be seen as a premarital step, a trial, one experience among others, or as an alternative to marriage. The second dimension targets the perception of parental attitudes on cohabitation by the women we interviewed. The spectrum of possible values ranges from perceiving parents to oppose cohabitation to assuming parents encourage such a choice.

We also introduced a third dimension to capture the individual's motivation to comply with the parents' wishes. This classification ranges from strong to weak motivation to comply. However, the question that inevitably emerges is why women should at all accommodate the views of their parents. Two theories currently prevail: the socialization theory and the social control theory. The first might explain part of the puzzle. It stipulates that parents affect their child's behavior through socialization. Preferences that parents have for their child shape the child's attitudes and values. Thus it might be the strength of family ties that explains the readiness of Italian adults to accommodate parental wishes, as assumed by previous research (Reher 1998; Bernardi 2003; Rosina and Fraboni 2004). The second theory holds that parents influence their children's behavior independently of the children's attitudes, using social control techniques. That is, some parents try to interfere in their children's choices to prevent undesired behavior by using methods such as punishment or rewards (Gecas and Seff 1990; Smith 1988). Conducting a study on the U.S. Axinn and Thornton (1993) found evidence for the social control hypothesis regarding entry into cohabitation. They suggest that adult children decide against cohabitation in order to meet parental expectations or to avoid negative sanctions, such as refusal of economic support. Young adults in particular might be more vulnerable to social control since they are not yet financially independent. In the Italian context, previous research assumes exactly the same connection (Di Giulio and Rosina 2004; Holdsworth and Irazoqui Solda 2002). In fact, Silverstein and Bengtson (1997) found that not only the actual exchange of goods is of importance but also the potential of future support. They use the term 'latent solidarity' to indicate that members of relationships with high levels of affinity also have the potential for future exchange - even if currently there is no such support. 
Based on these assumptions and earlier findings, we argue that both emotional and economic reasons account for the conformity of young adult with parental attitudes and desires. Our analyses aim to investigate women's motivation to comply in much more depth than do other studies on the subject by extracting the concrete factors that trigger women to behave according to their parent's wishes. In doing so, we organize our data analysis in a way that permits distinguishing between both factors: the emotional closeness of the parent-child relationship as well as the economic dependency on the family.

The three dimensions we employ are continuous rather than categorical, that is, the transition from one value to the other takes place along a spectrum. Further, we assume all dimensions to be time dependent: Women perceiving their parents to oppose cohabitation might find out that the opposition is perceived rather than real. If the opposition is a real one, parents might change their attitudes towards cohabitation e.g., when one of their adult children goes through divorce. Here, parents might be more open towards premarital relationships or living arrangements alternative to a formal union. Having witnessed a positive example of cohabitation in the extended family might also trigger a change in attitudes among parents. Individual perception of cohabitation might change over time too. Women who have entered cohabitation with the intention to marry soon after, might perceive cohabitation not to be that different to marriage. Consequently, they might abstain from the latter. Also the motivation to comply with parental wishes might change as incentives to conform change. Further, the dimensions we consider are interdependent, too. The willingness to accommodate parental desires might decrease, for instance, as women's perceptions towards cohabitation change: Women, who perceive cohabitation increasingly to constitute an alternative to marriage might be less likely to consider a future wedding than it was the case at the beginning of cohabitation. Women might also tend to reconsider their perception of cohabitation as parental attitudes towards informal unions change: Given a higher level of acceptance among the family of origin, interviewees might be inclined to reinterpret their union as a trial or passage rather than a premarital step.

In the next section of this paper, we plot interviewees according to their characteristics along the three dimensions. Our analyses revealed that women in Bologna and Cagliari employed relatively similar strategies when entering cohabitation. Thus we refer to the main clusters including women from both regional settings. Nonetheless, we shall emphasize existing differences among strategies used among women in Bologna and Cagliari. In particular, we want to know how individuals perceive parental attitudes, how important they regard their parents' desires, and how they finally realize their own desire for cohabitation. 


\section{Results}

We grouped the interviewees along all dimensions and found three main clusters (see Figure 3):

Striving towards conformity: In the first cluster there are women who see cohabitation as a premarital step. They have a strong motivation to comply with parental wishes and perceive that their parents have opposing attitudes on cohabitation. The vast majority of these women approached their parents when deciding to cohabit and had relatively close ties to their family of origin. Actually, after approaching their parents, they discovered that the parents indeed had negative attitudes towards cohabitation. Although all of these women decided for cohabitation as a premarital step, that is, their union was aimed towards marriage right from the start, parents had considerable difficulties with that choice. Parents tended to ask their daughters to marry right away.

- $\quad$ Clashing of attitudes: The second cluster contains women who also assume that their parents have rather opposing attitudes towards informal unions. However, these women have a weak motivation to comply with parental desires. This cluster is characterized by the fact that adult daughters tend to have different attitudes from their parents towards cohabitation - and this difference is rather longlasting. Whereas parents want their daughters to enter marriage, daughters choose cohabitation not as a premarital step but rather as an experience per se or even as alternative to marriage. These women do not respond to their parents' demands and tend to ignore the underlying disagreement (as in Bologna) or enter into dispute with their parents (as in Cagliari).

- $\quad$ Benefiting from parental support: In the third cluster we find women who perceive their parents to encourage entry into cohabitation. These women have a strong motivation to comply with the wishes of their parents and chose cohabitation as experience or alternative to marriage. In fact, these women experienced strong parental support when entering cohabitation. Although in some cases fathers were not satisfied with the cohabitation decision, mothers stepped in and convinced their husbands. The relations between parents and 
daughter, but especially those between mother and daughter, were characterized by strong ties. Both emotional and economic support were common among this cluster.

\section{Figure 3: Strategies identified among interviewees in Bologna and Cagliari}

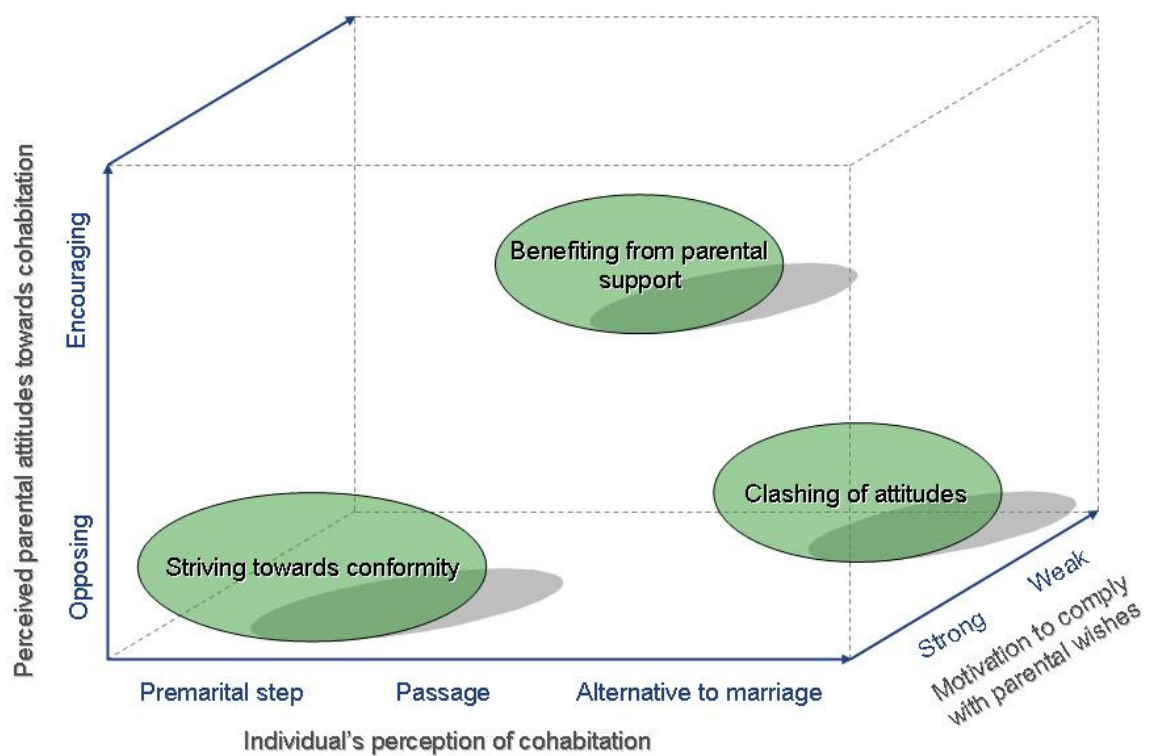

\subsection{Striving towards conformity}

Women who belong to the first cluster perceive cohabitation as a step that is aimed at marriage right from the start. All women in this cluster regard marriage as desirable. However, notable differences persist between interviewees living in Bologna and those living in Cagliari: The former decided purposely to live together before marriage. Most of them reported that they entered cohabitation because they wanted to spend more time with their partner or because of convenience: 
"We planned to live together and to marry anyway, also because my husband is not from Bologna, he's not from this city, thus it was difficult to meet - so the choice was made simply because we wanted to spend more time together"

"I did not have the rented flat anymore and instead of searching for a new one, we started to live together then."

Thus, their decision was based on a purposeful choice. Women in Cagliari, by contrast, often felt constrained to decide for a premarital union: In most cases, the couple's economic situation did not match the preconditions they considered necessary for marriage. These preconditions would include both partners having a more or less stable job and the opportunity to purchase a flat. Thus, though cohabitation was aimed at marriage, it did not necessarily end up in a conjugal union. Instead, the women experienced their informal union as a (sometimes long-lasting) passage:

"We wanted to stay together and for the wedding one needs more time, even if it was our plan (...) It was a whole range of things that lead us to live together, but it's not necessary before marriage. Absolutely not. At least in our case, we have known each other for a long time and we didn't need to live together to get to know each other."

"If we manage to stay economically secure, maybe one day we will marry."

All women in this cluster perceive that their parents oppose cohabitation and show a strong motivation to comply with parental wishes. In general, the parents wanted their daughters to marry right away. Several women of this cluster grew up in small villages, and their families continued to stay there. Although all of these women have lived in Bologna or Cagliari for many years, they are regularly confronted with the relatively closed attitudes of their parents. Most women declare themselves to be religious. However, especially Cagliarian women reported that - up to a certain extent - parents were able to relate to the decision in favor of cohabitation as the labor market situation was relatively tense in Sardinia.

Being aware of their parents' opposing attitudes on cohabitation, women in this cluster strove towards conformity. They, thus, declared their informal union as transitory passage before entering marriage. Most interviewees sought, in fact, parental acceptance. They tried to prepare their parents for the cohabitation by putting their 
intention carefully to their families, by entering slowly into the new living arrangement, and by calmly negotiating a solution. Emanuela, ${ }^{3}$ now aged 36, married and living in Bologna, announced that she had "grossi progetti" (big plans) such as marriage and having children. This conciliatory declaration reassured her parents and opened the way to informal union formation:

"[My parents] accepted it but for sure they are not enthusiastic about it because in the end they would have preferred marriage right from the start. But they understood the situation and did not stop me. They always said that they prefer marriage to us living together, but once we told them what we wanted to do, even they were o.k. with our decision."

This way, cohabitation generally serves as a premarital living arrangement that evolves into marriage. The possible failure of this premarital cohabitation - expressed in some couples' separation - is not taken into consideration at all. From the outset, cohabitation is on target for marriage. In Emanuela's case, we assume that an informal union that was not aimed at marriage would have caused many more problems and difficulties with her parents. Emanuela managed to negotiate a compromise, as did most other women in this cluster. However, the compromise is only temporary, as parents accept cohabitation for the time being but not for an indefinite period.

At some point, parents usually tended to (re)inquire whether the daughter is intending to marry. Especially in Bologna, daughters generally gave in and finally decided to have a wedding. In Cagliari, though, parents often had to accept relatively long-lasting cohabitations as the economic situation of their adult child impeded a wedding. Nonetheless, parents generally continued to expect marriage, as in the case of Viviana (36 and still cohabiting). As her mother understood the necessity to save money for the wedding party, she gave her temporary agreement. However, she continued to insist on marriage:

"My mother is waiting that we marry, because, of course, she has a certain mentality. She does not agree very much with living together before getting married, although she understands very well that this is the situation we are in right now, a necessary transitional stage, as the marriage demands much more time. But of course, what she's asking me every time we meet, is 'well, and the marriage?"

\footnotetext{
${ }^{3}$ For reasons of anonymity, we have changed the names of our interviewees and of all the people they talked about. This applies also to islands, cities, and villages.
} 
Interestingly, when discussing cohabitation and marriage, it is the mother, almost exclusively, who makes the approach to the couple. In most cases the mother rather than the father acts as the direct negotiator. In turn, women in the sample also tended to refer to their mothers, rather than their fathers, when announcing intentions or decisions. In fact, all mothers of this cluster were married and as interviewees reported, they tended to discourage their daughters from cohabitation and encouraged them to enter a conjugal union right away. Almost all interviewees described their families as "traditional" with having a rather "closed mentality":

"I grew up in a very traditional family, in the South of Italy, thus in an atmosphere very different to where I live today, very traditionalistic, very closed. It was a small village in the South, with a very restricted mentality. Thus, with certain things I had many restrictions during my youth. Up to a certain age I could not even go out with boys and such things."

“[My parents] are ... I don't say rigid, but less open. The principles of the family on certain roles, on certain things ... have always been fixed, all in all."

In fact, most mothers in this cluster were housewives throughout their lives. As regards parental education, based on our short questionnaires we observe that low levels of education among both mothers and fathers are common among this cluster, although this does not apply to all parents. We assume that the rather closed mentality of parents is a result of their isolation from modern attitudes and behaviors. Many families live in small villages and only have contact with people with the same traditional attitudes and values. In addition, mothers tend to have even fewer opportunities to mingle with people of modern attitudes and behaviors, as they usually have fewer contacts outside their home.

Women belonging to this cluster show a strong desire for parental approval, as demonstrated by the experience of Patrizia, age 38, cohabiting and living in Cagliari. Patrizia perceived her parents to have negative attitudes towards informal unions. As a consequence, she was not open to cohabitation. Surprisingly, one day Patrizia's mother proposed cohabitation:

“... when I came back one morning my mother said to me: 'But why don't you go and live with him?' and I took this advantage, I snapped at the chance and left. What my parents might have thought, was a big impediment for me. I knew that they were against it and I didn't want to make them sad. The moment I had almost their agreement, I left." 
Parental approval was crucial for Patrizia's decision to leave home and to move to her partner's flat. Furthermore, she emphasized that previously she had set that choice aside since she did not want to hurt her parents' feelings:

“... I did not want to make them sad and I didn't feel like breaking up completely. With their agreement I felt calmer and I have done it."

Most women of this cluster, both in Bologna and Cagliari, reported that they had rather intensive relationships with their families. Some interviewees visited their families and home villages every two to three weeks. Sometimes this behavior was driven by the desire to see their family; in other cases it was caused by parental need for support and care. Several quotes demonstrate the high importance family has. The family is seen as pivot for the most important decisions in life, among them the decision to leave home and the choice of when and how to enter a couple relationship. It is not surprising that adult children face difficulties in announcing their intention to enter an informal union. Women emphasized for instance, that they would not be able to bear any tensions with their family:

"I would suffer a lot, if I struggled with anybody of my family, now and in the future. I wouldn't manage to sustain it."

Clearly, all these women regarded their families as very important. These strong emotional ties between adult daughters and parents - especially mothers - explain the power of parents.

Analyzing the economic situation of women in this cluster however, we found major differences between Bologna and Cagliari. Women living in Bologna had a more or less stable employment position and were economically independent (including when entering cohabitation). Women received economic support, mainly for the purchase of a flat/apartment, home renovation and/ or furniture. Interestingly, in nearly all cases support was given, but strongly connected to the actual marriage: either shortly before the wedding or afterwards. Nevertheless, no single woman emphasized such a relation. It seems that in Bologna it is not economic dependence per se that explains a young adult's accommodation but the prospect of financial help to meet housing and furniture needs. Non-economic support is an important factor as well. Women, for instance, had support after childbirth. In today's Italy non-economic support, such as childcare, is highly important for young families. Women know that they have to rely on families' non-economic support when having children, all the more if they wish to continue work. This fact might promote accommodation towards parents' wishes too. 
As to Cagliari, most interviewees had been supported economically already prior to the time of entering cohabitation. It is striking that the male partner's family usually contributed to the purchase of a flat, whereas the woman's family tended to pay for the furniture. Although support is given at the beginning of cohabitation, it is often aimed at the couple's future. Even though there is no promise to marry, parents seem to invest their money with the prospect of a future wedding - as shown for instance in the statement by Patrizia's father. Disappointed about the fact that his daughter still did not enter marriage, he said, "If I would have known, I wouldn't have done it." For most couples in Cagliari economic support by families is crucial. The peculiarities of the Italian welfare state contribute to the great importance of the family as provider of social security. In this regard, it is critical whether the family supports an adult child or not. Thus, the relation to parents and economic security are highly interwoven. We found that parents tended to support more extensively when they expected their daughter to marry. However, the peculiarities of the Italian welfare state together with the Italian housing situation generate excrescences that cause huge difficulties for couples: A tight housing situation plus a scarce social security system leads to the possibility of parents intruding into a couple's affairs. It is not uncommon for parents to make use of such an opportunity, thus restricting the couple's liberty; sometimes parents donated building land to their child in order to push for living near to the family of origin. Sometimes parents provided an already-owned flat for the couple. However, only parents decided what to renovate within the flat and in which manner.

It seems, in fact, that the motivation of young adults to comply with their parents is the result of two factors: First, all women in this cluster show very strong family ties. As a consequence, they strove towards conformity with their parents. Second, economic and non-economic support appears to be another incentive. Parents spent high amounts of money on furniture or housing. The prospect of such help (as in the case of Bologna) as well as the individually perceived commitment towards the parents (as in the case of Cagliari) might induce adult children to take the step their parents expect them to make.

\subsection{Clashing of attitudes}

Among this cluster we find women who also perceived that their parents opposed cohabitation. However, one major difference between this and the previous cluster is the motivation to comply with parental wishes. Whereas women in the previous cluster showed strong motivation, those in this cluster tended to have a weak motivation to comply with parental desires. These women did not act in line with their parents' wishes on family formation. They perceived cohabitation not simply as a premarital step, but rather as a trial, or even as an alternative to marriage (in fact, some cohabiting 
women had already given birth to their first children). None of these women had decided for marriage so far, although some of them might opt for a marital union later on. Thus, they differ from the first cluster in that their union was not aimed at marriage right from the start.

Especially women living in Bologna reported that parents usually did not pressure their adult daughters to enter marriage. Thus, the conflict between both parties had not broken out (yet it lingered at the subliminal level). Parents only sporadically encouraged marriage. This encouragement, however, had little influence on adult children. In general, women tended to ignore the fact that their parents were against cohabitation.

Parents in Cagliari reacted quite differently. The women were faced with strong, negative reactions from the family when entering an informal union or even when announcing the intention to cohabit. Some interviewees were afraid to tell their parents about their informal union. Although all the women had expected strong reactions, they still decided for cohabitation. They had a low motivation to comply with the wishes of their parents. In fact, all women in this cluster had stood up to their parents as far as cohabitation was concerned. Whereas some parents became resigned to it after several years, others did not settle easily with their daughter's choice. By far the most resistance was encountered by Fabiola (44). When she left home for cohabitation her mother strongly rebelled against that choice. In the end, the relation between daughter and mother started to shut down completely and the whole family suffered in that situation.

"I had problems with my mother who did not accept that I started living with a man. Thus, for several years the relation with my mother was non-existent (...) For my mother it was important that I 'would leave home in my wedding gown', but this had no importance for me (...) In fact, the first I lived with someone, the whole family suffered of the problems I had with my mother, because I wasn't there at lunches, at festivities, at Christmas."

It seems that for Fabiola's mother it was more important to enforce the commonly accepted way to leave home - namely via marriage (which was contrary to Fabiola's intentions) - than to keep a good relationship with her own daughter. Also when she lost contact with Fabiola, the mother did not reconsider her attitude. Obviously marriage was so important for Fabiola's mother that she was willing to risk the consequences of her rigid action. It is striking that Fabiola, as well as other Cagliarian interviewees, characterized their mothers as being very strict, dominant, or rigid. It was especially the mothers who had problems in accepting their daughter's choice for cohabitation. Generally they never thought of the possibility that their daughter might 
leave home before marriage. Often they were disappointed, frightened and tried to convince their daughters to rethink their decisions. These mothers asked their daughters to 'regularize' their union and finish with this phase of 'uncertainty'. Though Cagliarian fathers often held the same position as their wives towards cohabitation, they frequently reacted in another way. In Fabiola's case it was actually the father who took the initiative and convinced his wife step-by-step to rebuild relations with their daughter. After three to four years the relationship started to improve. Some interviewees emphasized that their father had finally become aware that his daughter had reached an age where she was able to decide on her own which path to take. Although often having an opposing attitude, fathers conceded to allow the daughters to learn from the experience. However when doing so, they made the point that in the end their daughter had to answer for her own mistakes:

"He told me 'In principle you are an adult person', at that time I was 32 and 'you are grown-up, if necessary you need to pay for your choices'."

In contrast to mothers, fathers in Cagliari were often perceived and described as affectionate and as respecting the daughter's decisions. It is remarkable that despite these differences, interviewees mainly confided in their mothers when choosing to live in an informal union. However, this behavior seems to be part of the Sardinian family tradition: In Sardinia, mothers always used to have a high decision-making autonomy (Oppo 1991, 1992). Among this cluster (but also among the whole Cagliari sample), women rarely addressed their father directly. Fabiola, actually, believed in a relation between parental attitudes and their personal experiences of life:

"He was an artist, thus he was very open, whereas my mother was a housewife. She stayed at home, took care of the children and had no opportunity to open up mentally. She visited the nuns, who were almost the same. They were actually a pillar for this mentality. Thus, my father had his experiences outside home and managed to accept - very respectfully - the decisions his children took: 'All the things that are o.k. for you, are also o.k. for me. The important thing is that you are fine'. And my mother, on the other hand, was like: 'No, I want my daughter to do this and if not, I will have nothing to do with her'."

The commonly negative attitude of parents towards modern living arrangements such as cohabitation seems to be connected to their relative isolation from societal innovations. Most of them, both in Bologna and Cagliari, lived in smaller villages; they generally had low or middle levels of education, and mothers tended to be housewives. Moreover, religious traditions and canons were important for them. The higher 
acceptance of informal unions among fathers might be explained partially by their higher exchange of information and attitudes at work. With reference to this rather closed mentality, it is not surprising that some parents opted for hiding the informal union of their daughter to the entire family. Interviewees, for instance, reported that none of her family members - apart from her parents - knew that she cohabited.

As to family relations, we observed that in most cases the child-parent relationship was tense, not only in respect to the underlying or open conflict but also past family relations. It is striking that almost none of these women were in the habit of relying on their parents when having problems or when taking important decisions. Generally these women had weak ties to their families and parents. Barbara (32 and living in Cagliari), for instance, stated that in her view family relations were often burdened by feelings of guilt and emotional blackmail:

"As I see the family as it is structured at the moment, it doesn't have much sense ... I prefer to see families composed by people who decided to live together. The relationship between parents and children, for God's sake, are loaded by many positive things. However, other factors come into play as well, such as feelings of guilt, let's say, emotional blackmail (...) For sure, there are also families that do not fall into this category, but I think that the major part does."

Valeria (age 40 and living in Bologna), on the other hand, had experienced serious quarrels with her parents when a teenager. When deciding to leave home and to start studying, she refused any support from her parents. Especially in the Italian welfare state, which focuses on the family as the main actor of solidarity, this decision had strong consequences for her. Valeria had to make demanding efforts to overcome her economic problems and to finish university. As a result, step by step, Valeria gained her parents' respect. This respect allowed her to decide independently about her life - even if her parents had a completely different point of view:

"... I know that this is the result of exhausting and painful work, because I also had ... moments - in the past when I felt vulnerable, with problems, even some big ones, also some economic ones and ... it wasn't easy to have ... in addition it was very difficult for me to say 'Mum, Dad, I'm in a deep mess, help me'. Thus, it was quite hard, ... but it developed this kind of relationship which I like a lot, of great respect, so I think that ... maybe they have the desire, but ... because of a question of respect for my choices they never entered it, I mean also regarding the fact that I have a child out-of-wedlock, my mother never ever influenced ..." 
The early emotional and economic separation from her family allowed Valeria to develop a relationship with her parents that was characterized by a high degree of equality. In the latter case, the breakup of conventional support patterns gave way to independent decision-making about family formation.

Interestingly, only women in this cluster perceived and emphasized a connection between parental economic support and parental interference in the relationship. Thus, most of these women avoided financial help, if they could. Only a few younger ones were constrained to rely on financial assistance from their parents - and were often afflicted with that situation. One interviewee from Bologna, Marcella (29), pointed to the direct connection between economic support and demand for non-economic support:

“... if they help you there is always a price to pay $\{$ laugh $\}$, that means that they give you..., but they also ask you for something in return (...) in the end, for sure, there is always a power relation. It's always like that ... in the end it's the money."

Thus, most women in Bologna and Cagliari were already financially independent when deciding for cohabitation. These women were not financially supported when entering their informal union. Whereas parents of the first cluster offered support for housing and furniture, these parents did not. Some of the interviewees pointed out that since there was no approval of cohabitation, there was no help for realizing it:

"I bought everything, for instance the pots and all things of that kind. I bought everything. Because, not agreeing completely [with cohabitation], there was no such help."

Two factors seem to explain the different consequences of cohabitation for these women: First, the affective distance between parents and child and second, the absence of economic dependence. Thus, neither socialization nor social control techniques induced interviewees to act in accordance with parental desires. These adults simply ignored conventions. As a result, we find a high potential for social change among this cluster. Actually, previous research in the U.S. found that children with distant relationships with their parents were more likely to behave in ways that contradict their parent's expectations (Myers 1996; Weinstein and Thornton 1989). 


\subsection{Benefiting from parental support}

A third pattern of behavior observed is 'benefiting from parental support.' Women belonging to this cluster have a strong motivation to comply with parental wishes and perceive encouraging attitudes towards cohabitation. One major difference compared to the first and second cluster is the fact that parents in this cluster supported their daughters when entering cohabitation and even pushed them to take this step. These parents tended to have relatively tolerant attitudes on cohabitation - this applied also to informal unions that were not aimed at marriage at all. Most women decided for cohabitation as trial, passage, or alternative to marriage. This cluster is mainly distinguished by the transmission of values of independence by mothers, as in the case of Erica (age 33, married and living in Cagliari), who experienced the separation of her parents during her youth. She emphasized this:

"I lived alone with my mother, with an independent woman who taught me independence and to value myself."

Valentina (52 and living in Cagliari too) also stressed the respect her parents had towards her decisions - this applied especially to her mother, who loomed large in her life. Valentina admired her for always having an opinion of her own - sometimes even opposing her husband - although she had always been a housewife and therefore dependent on him. Valentina describes her mother as follows:

"She's a very liberal woman, although she grew up with a certain education, she has always been ... my mother is one of there maybe few persons at her age who for personal conviction - was in favor of abortion. Although believing and being a person with a certain culture, she has been a person who has always chosen. It's not by accident that I have certain convictions. I believe that the maternal education has a lot of influence. My mother is 85 years old and she's one person at her age who had a liberal mind and who proved that, although she's a person who was a housewife throughout her life ... she's a woman with lots of capacity and a lot of intelligence, maybe one of the few ... that I got to know. And I mean, it's relatively easy to demonstrate certain ideas when you have a profession, when you are independent, when you have already reached something in your life (...) to have determined convictions and to be against also against those convictions of the husband wasn't easy."

Mothers of this cluster - particularly those coming from Bologna, but also some mothers living in Cagliari - have themselves experienced cohabitation, separation, divorce, or remarriage. They had cohabited or separated in years past and some of them 
were among the first who used the option of legal divorce, introduced in Italy in $1970 .^{4}$ These mothers can be seen as constituting a select group, since both cohabitation and divorce was even less diffused at that time. In fact, Goldscheider and Goldscheider (1989) assume that parents who went through the divorce revolution welcome a 'new life course' for their children. Parents in this cluster often had a very high level of education (university degree) and in some cases mothers had a higher education than their partner. Moreover, mothers were largely employed and worked as teacher, whitecollar worker, or freelancer. Despite the above peculiarities among the parent generation, the mothers/ parents were neither younger than other mothers/ parents among our sample, nor did they necessarily have a higher social status. We rather observe the opposite effect: Twenty to thirty years ago, mothers who have experienced cohabitation or went through separation or divorce suffered from social stigmatization. Besides this social downgrading, mothers in this cluster had less economic means at their disposal, too - given that usually they alone were responsible for the family's income. Thus, supporting their adult daughter when entering cohabitation was at least equally expensive for them as it was for other families.

Again, daughters confided in their mothers when taking important choices. But in contrast to the first pattern presented (see section 4.1), these mothers often supported their daughters when entering cohabitation. Most probably, mothers would not even disagree should their daughters decide to give birth outside marriage. Although none of the women in this cluster had a child yet, several were thinking of having offspring soon. These women generally did not expect their parents to have opposing attitudes on that choice. The acceptance of the adult daughter's decisions by parents was also rooted in the respect and confidence parents had for their child. Recurrently women emphasized this aspect:

"As to that, however, they never tried to hinder me and from my point of view they respect me and hence I respect them."

“... they always used to trust in my judgment, so if it was o.k. for me it was o.k. for them, too."

Thus, in contrast to the previous cluster (section 4.2), women had strong emotional ties to their parents - particularly to their mothers. This was also found among the first cluster. Frequently this strong mother-daughter bond had its origin in the kind of living arrangement both experienced during the daughter's childhood and youth: Since some

\footnotetext{
${ }^{4}$ Despite strong opposition of the Christian Democrats and the Catholic Church, the Italian government passed the divorce law in 1970. A referendum failed in 1974.
} 
mothers were separated or divorced, they reared their daughter on their own. Fathers had generally no or much less importance; this strengthened, of course, the motherdaughter tie. Actually, previous research supposes that female-headed households exhibit unusually low intergenerational conflict (Goldscheider and Goldscheider 1989).

A different pattern, though, was found in Cagliari. Here, mothers often acted as mediator between father and daughter. When Alice (31), for instance, announced her plan to enter cohabitation, her father protested strongly. This was particularly delicate as Alice partly depended economically on her parents. Her father threatened her with cutting all economic support and argued that at the moment she started living with her partner, she should be economically independent. In the end, Alice's mother stepped in and convinced her husband to accept their daughter's choice. He even agreed to continue to support his daughter if necessary. The behavior of Alice's mother is interesting as she suggested that her daughter enters a premarital cohabitation before deciding to marry:

"Yes, I first talked to my mother, because she's a much more open person. My mother has fewer, how to say, social prejudices. She is more understanding. I first talked to her about it, I told her the situation and she absolutely agrees with me, better, I have to be honest, my mother actually advised me to live with someone before I get married. She told me: 'My daughter, it is not necessary that you marry' - almost preventing. I don't know whether this is because of personal experiences or not, but let's say, she's more content that I start cohabiting."

Among this cluster, the mothers of our interviewees had a decisive role: They educated their daughters towards independence and autonomy. Several mothers exemplified this autonomy to their daughters throughout their own life by being employed and hence economically independent. Especially Valentina (quoted above) pointed to the relationship between being employed and representing one's own convictions even when in contrast to the belief of others. Additionally, these mothers supported their daughters emotionally when they decided for an unconventional way of living - also against the father's conviction. In general, women in this cluster were always supported by their families when there was a need. This applied to both economic and emotional support. Sabina, for instance, was able to leave home and to start living with some friends when she was in her twenties. Later, her parents bought a flat where she lived on her own. Women living in Bologna, though, generally abstained from financial help. The renunciation of financial help was often motivated by the fact that parents were already supporting them (often for their education) and daughters found it embarrassing to ask for further help. If parents were willing to provide support nevertheless, women in this cluster generally accepted it, but with hesitance. Eleonora, 
for instance, insisted on paying a monthly rent to her parents when living in their second flat. Only after several years, when her parents decided to sign it over to her, did she stop paying the money.

As in the first cluster, women in this cluster were strongly influenced by their parents. The mechanism, however, worked differently. Family formation experiences of mothers and the strong mother-daughter bond induced women to have tolerant attitudes on family formation too. Interestingly, none of the women perceived their mother's living arrangement as something bad or unacceptable. Their knowledge about the mother's way of life (e.g. experiencing a family model other than the classic one), led women to behave in a similar way. In contrast, parental influence through economic support was of no importance here. It seems, in fact, that parents and especially mothers influenced their daughters via socialization, but much less so via social control techniques.

\section{Summary}

For the systematic analysis of parental influence on cohabitation, we employed the 'theory of reasoned action' by Ajzen and Fishbein (1980). Relying on their assumptions, we build a three-dimensional diagram including individuals' perception of cohabitation, perceived parental attitudes, and motivation to comply with parents' wishes.

The analysis reveals the different levels of acceptance that parents had with regard to cohabitation. Traditionally-oriented parents tended to criticize the informal union of their adult daughters, although the daughters themselves defined their cohabitation to constitute a premarital step. Parents with modern values and attitudes, in contrast, accepted any kind of cohabitation, i.e., cohabitation as alternative to marriage or as a trial. And they did so without imposing any conditions.

As regards parental attitudes, we observed that among both samples the same factors seemed to have shaped parental opinions towards cohabitation: Daughters with parents of lower education, including mothers who were housewives and/or had come from rural areas, experienced the strongest parental protest when they entered informal union. By contrast, interviewees who grew up in the cities of Bologna or Cagliari, women with more highly educated parents and those with employed mothers faced much fewer (if any) difficulties with their parents. Moreover, especially for Bologna we found that women whose mothers experienced living arrangements other than the traditional one were encouraged by their mothers to enter informal union. These findings are in line with studies that found evidence for the impact of parental education (Rosina and Fraboni 2004; Schröder 2006; Di Giulio and Rosina 2007) and living 
arrangements of the family of origin (Domínguez et al. 2007) on cohabitation in Italy. However, as our study is not representative, further quantitative research is essential to strengthen these qualitative insights.

Among both samples, mothers had a decisive role when it came to informal union formation as daughters were used to approaching their mothers when taking important decisions. Mothers who opposed cohabitation tended to discourage their daughter from cohabitation. These mothers tried to convince their adult children to enter marriage as soon as possible. Mothers with positive evaluations of cohabitation, on the other side, agreed to entry into informal union - some even encouraged their daughters to dare this step. This mechanism seems to be stronger in Cagliari than in Bologna: In cases where mothers opposed cohabitation and fathers agreed, daughters faced much more difficulty when choosing cohabitation. Whereas in cases where mothers agreed and fathers opposed, mothers generally convinced their husband to accept cohabitation. The strong power of mothers in Sardinia might be explained by the traditionally higher decisionmaking autonomy of wives (Oppo 1991, 1992). Previous research from the United States provides evidence of a strong mother-daughter bond. It has been found that after they have left their parental home, daughters have a more intensive relationship with their mothers than do sons (Greene and Boxer 1986). Furthermore, mothers' preferences and attitudes exert a strong influence on the family formation process of their daughters, e.g. the timing of first birth and the final number of children independently of the adult child's own preferences (Barber 2000; Barber and Axinn 1998; Axinn et al. 1994). Axinn and Thornton (1993) assume that daughters are more inclined than sons to see their mothers as role models and thus behave in accordance with their mothers' opinion. According to social learning theory, girls learn to be like their mothers by consistently and positively being reinforced when they imitate their mothers' behavior (Boyd 1989, referring to Weitzman 1984).

We found that in both settings the way young women perceive their informal union is highly interwoven with their motivation to comply with parental desires. The more daughters perceive their parents to oppose cohabitation and the stronger their motivation to satisfy their parents, the more probable it is that they will aim their cohabitation at marriage. Whereas women in the Bologna sample entered marriage this way - only after several months of cohabitation, women in Cagliari tended to postpone the marriage until their economic conditions allowed for celebrating the wedding. Interviewees, who perceived their parents - and especially their mothers - to have favorable attitudes towards cohabitation and who, in general, had a high motivation to comply with parents, saw their informal union rather as a passage or as alternative to marriage. And, last but not least, those women with a weak motivation to comply with parental desires did not satisfy parental wishes for marriage. This applied in both regional settings. These women chose a lifestyle that was completely different from that 
of their parents. Here we find the highest potential for future changes in family formation behavior.

Interestingly, the motivation to comply with parents seems to depend on two major factors. The first, and obviously more important, factor regards the strength of family ties; the second one refers to past, current, and future economic support from parents. Women in the first and third clusters were strongly bound to their parents, unlike women in the second cluster. Whereas adult daughters with strong emotional attachment to their parents tended to replicate their parents' attitudes on family formation, daughters with shattered relations generally developed value orientations that contradicted those of their parents. Their motivation to comply with parental desires was much lower. In short: Only parents with good relations to their offspring transmitted their own values successfully.

As regards economic factors, we found less clear evidence. However, our findings indicate that economic (in)dependence does play a role when deciding for an informal union: Women in the second cluster - those with tense family relations - emphasized the connection between parental economic support and interference. Thus they perceived the potential of economic help as a means to bring pressure to bear on them. Given this awareness, the women tended to avoid any economic support. And the parents refused to support their daughters since they did not approve cohabitation. Of course, one might argue that such refusal is mainly the result of weak family ties between adult daughters and parents. However, it is also true that young Italians can only decide for cohabitation if their family supports that choice or if they are financially independent. The Cagliarian sample is a case in point: Here, parental help was crucial as the labor market situation did not allow for stable economic independence. This help, though, was generally aimed at marriage, although couples did not always declare their intention to marry soon or even at all. The daughter's family tended to provide support to buy furniture, whereas the male's family contributed to housing costs, such as prepayments. The granting of past, current, and future economic support seemed to induce many couples to finally decide in favor of a wedding.

Additionally, external factors such as housing and the employment situation had a stronger impact on young adults in Cagliari than was the case in Bologna. The lack of adequate and affordable housing as well as missing job opportunities strengthens the importance of the family as provider of social security. As a consequence, young adults in Cagliari face stronger barriers when leaving the parental home. Actually, leaving home is the first big step to take when intending to live in an informal union. It is not surprising then, that most Cagliarian couples had very long-lasting relationships before they entered cohabitation, whereas this was not the case in Bologna. 


\section{Discussion}

The analysis, especially of the Cagliari context, shows how much several factors impact the diffusion of cohabitation and how strongly they are interwoven. External circumstances such as housing and employment market reinforce the power parents have on their children. Not having the opportunity to leave home and earn money leads to an increased importance of parental support. In Bologna, in contrast, young adults have more of these opportunities. Thus, a complexity of factors hinders young adults in Cagliari from deciding for an informal union. In Bologna this is the case too - however, to a lower extent. It seems that, compared to Cagliari, young adults in Bologna have more opportunity to act in line with their attitudes concerning union formation. We assume that, due to the factors cited here, a high proportion of young adults in Sardinia step back from cohabitation. Our findings confirm, in fact, that it is not sufficient to analyze informal union formation in Italy on a national level. The regional perspective revealed strong differences in the way diffusion of cohabitation is influenced in both contexts of the study.

However, given our sampling strategy, our study has some limitations: In light of the fact that our sample includes primarily highly educated women, we cannot analyze how women of lower education perceive the influence of their parents and how they react to it. Further, we have no information on women who entered marriage directly as well as on those who experienced the end of a previous cohabitation. Consequently, we cannot investigate whether or not, and if so, how the family relations impacted the union formation decisions of these adults. Since we employed a retrospective approach, our interviews bear the risk of incomplete or selective remembrance. This might be true especially for those interviewees, who had entered cohabitation and marriage many years before the date of interview. However, because family and family relations are a major issue in the lives of most interviewed women and as cohabitation and marriage are among the most important events in women's' lives, we assume that the memory on these topics is relatively vivid.

The observed behavior of postponing cohabitation has serious implications for other demographic events in Italy: The later young adults can afford to start living with their partners, the later they enter cohabitation, marriage, and parenthood. Our qualitative data, which is not representative of course, showed that interviewees in Bologna gave first birth on average at age 31.5; interviewees in Cagliari did so at approximately age 34. In addition, several interviewees were not aware of the fact that their 'biological clock' restricted fertility. Some women at age 40 still intended to have their first child "somewhere in the future." Especially among the Cagliari sample we found women who started trying to conceive very late in life. Their attempt resulted in unwanted childlessness. In this respect, the slow and hampered diffusion of 
cohabitation needs to be considered in relation to the low rates of fertility that have started to be typical for Italy.

Regarding the future development of cohabitation in Italy, this study indicates further growth in the practice. Our findings point to the importance of parental levels of education and mothers' labor market activities in the acceptance of cohabitation. We assume that the increasing numbers of more highly educated and working mothers will accelerate non-traditional living arrangements such as cohabitation. Nevertheless, this change will probably take some time.

Since our analyses provide evidence for the strong influence of the emotional bonds between adult children and their parents on informal union formation, the incorporation of questions on this topic into survey questionnaires would certainly be useful for future research. Some studies on family formation practices in Italy and Spain have already started to enlarge on the role of family ties (see, for instance, Bernardi et al. 2007 or Holdsworth 2005). As did our work, these studies rely on qualitative research approaches. In order to strengthen our findings on the importance of emotional bonds between family members on union and family formation processes, further quantitative research is necessary.

\section{Acknowledgements}

For their useful advice and suggestions I am grateful to Laura Bernardi, Peter A. Berger, Sylvia Keim, Andreas Klärner, Monika Mynarska, Paola Di Giulio, Esther Geisler and Wenke Apt. I also highly appreciate the comments made by Alessandro Rosina when presenting an earlier version of this paper at the Giornate di Studio sulla Popolazione 2007. This article further benefited from the highly valuable comments given by two anonymous reviewers of Demographic Research. For language editing I thank Susann Backer and David Harrison. This paper is part of a dissertation project, which was funded by the Max Planck Institute for Demographic Research in Rostock (Germany) and by the land Mecklenburg-Western Pomerania. 


\section{Bibliography}

Ajzen, I. and Fishbein, M. (1980). Understanding attitudes and predicting social behavior. Englewood Cliffs, NJ: Prentice-Hall.

Axinn, W.G., Clarkberg, M.E. and Thornton, A. (1994). Family influences on family size preferences. Demography 31(1): 65-79.

Axinn, W.G. and Thornton, A. (1993). Mothers, children, and cohabitation: The intergenerational effects of attitudes and behavior. American Sociological Review 58(2): 233-246.

Barber, J.S. (2000). Intergenerational influences on the entry into parenthood: Mothers' preferences for family and nonfamily behavior. Social Forces 79(1): 319-348.

Barber, J.S. and Axinn, W.G. (1998). The impact of parental pressure for grandchildren on young people's entry into cohabitation and marriage. Population Studies 52(2): 129-144.

Bernardi, L. (2003). Channels of social influence on reproduction. Population Research and Policy Review 22(5-6): 527-555.

Bernardi, L., Gabrielli, G., Oppo, A. and Gribaldo, A. (2007). Socialization to parenthood: A case study comparison. Paper presented at the $72^{\text {nd }}$ Annual Meeting of the Population Association of America, New York City, USA, March 29-31 2007.

Bernardi, F. and Nazio, T. (2005). Globalization and the transition to adulthood in Italy. In: Blossfeld, H.-P., Klijzing, E., Mills, M. and Kurz, K. (eds.). Globalization, uncertainty and youth in society. London: Routledge: 349-374.

Billari, F.C. (2004). Becoming an adult in Europe: A macro(/micro)-demographic perspective. Demographic Research S3(2): 15-44.

Billari, F.C., Castiglioni, M., Castro Martin, T., Michielin, F. and Ongaro, F. (2000). Household and union formation in a Mediterranean fashion: Italy and Spain. Paper presented at the FFS-Flagship Conference "Partnership and fertility - a revolution?”, Brussels, Belgium, May 29-31 2000.

Billari, F.C. and Rosina, A. (2005). "Mamma" and the diffusion of cohabitation: The Italian case. Paper presented at the $70^{\text {th }}$ Annual Meeting of the Population Association of America, Philadelphia, USA, March 31-April 22005.

Boyd, C.J. (1989). Mothers and daughters: A discussion of theory and research. Journal of Marriage and the Family 51(2): 291-301. 
Charmaz, K. (2000). Grounded theory: Objectivist and constructivist methods. In: Denzin, N.K. and Lincoln, Y.S. (eds.). Handbook of qualitative research. $2^{\text {nd }}$ ed. Thousand Oaks: Sage: 509-535.

De Sandre, P., Ongaro, F., Rettaroli, R. and Salvini, S. (1997). Passaggi lenti all'autonomia della vita adulta. In: Matrimonio e figli: tra rinvio e rinuncia. De Sandre, P., Ongaro, F., Rettaroli, R. and Salvini, S. (eds.). Bologna: Il Mulino: 57-90.

Di Giulio, P. and Rosina, A. (2007). Intergenerational family ties and the diffusion of cohabitation in Italy. Demographic Research 16(14): 441-468.

Di Giulio, P. and Rosina, A. (2004). Innovative behavior in Italy: Parents' influence in the choice of type of first union. Paper presented at the $69^{\text {th }}$ Annual Meeting of the Population Association of America, Boston, USA, April 1-3 2004.

Dominguez, M., Castro Martin, T. and Mencarini, L. (2007). European latecomers: Cohabitation in Italy and Spain. Paper presented at the $72^{\text {nd }}$ Annual Meeting of the Population Association of America, New York City, USA, March 29-31 2007.

Ferrera, M. (1996). The "Southern Model" of welfare in social Europe. Journal of European Social Policy 6(1): 17-37.

Gecas, V. and Seff, M.A. (1990). Families and adolescents: A review of the 1980s. Journal of Marriage and the Family 52(4): 941-958.

Glaser, B.G. and Strauss, A.L. (1967). The discovery of grounded theory: strategies for qualitative research. Chicago: Aldine.

Goldscheider, F.K. and Goldscheider, C. (1989). Family structure and conflict: Nestleaving expectations of young adults and their parents. Journal of Marriage and the Family 51(1): 87-97.

Greene, A.L. and Boxer, A.M. (1986). Daughters and sons as young adults: Restructuring the ties that bind. In: Datan, N., Greene, A.L. and Reese, H.W. (eds.). Life-span developmental psychology: Intergenerational relations. Hillsdale, NJ: Lawrence Erlbaum: 125-149.

Holdsworth, C. (2005). When are the children going to leave home!: Family culture and delayed transitions in Spain. European Societies 7(4): 547-566.

Holdsworth, C. and Irazoqui Solda, M. (2002). First housing moves in Spain: An analysis of leaving home and first housing acquisition. European Journal of Population 18(1): 1-20. 
ISTAT. (2001). Censimento 2001, available at: http://www.istat.it/

Kiernan, K. (2004). Unmarried cohabitation and parenthood: Here to stay? European perspectives. In: Moynihan, D.P., Smeeding, T.M. and Rainwater, L. (eds.). The future of the family. New York: Russell Sage Foundation: 66-95.

Kiernan, K. (1999). Cohabitation in Western Europe. Population Trends 96: 25-32.

Myers, S.M. (1996). An interactive model of religiosity inheritance: The importance of family context. American Sociological Review 61(5): 858-866.

Onagro, F. (2004). Prima della scelta: La lunga transizione. In: Accademia Nazionale dei Lincei (ed.). La bassa fecondità tra costrizioni economiche e cambio di valori: Convegno internazionale (Roma, 15-16 maggio 2003). Roma: Accademia Nazionale dei Lincei: 45-69 (Atti dei convegni Lincei; 202).

Oppo, A. (1992). Dove non c'è donna non c'è casa: Lineamenti della famiglia agropastorale in Sardegna. In: Barbagli, M. and Kertzer, D.I. (eds.). Storia della famiglia italiana 1750-1950. Bologna: Il Mulino: 191-218 (Prismi).

Oppo, A. (1991). Madri, figlie e sorelle: solidarietà parentali in Sardegna. POLIS V(1): 21-48.

Reher, D. (1998). Family ties in Western Europe: persistent contrasts. Population and Development Review 24(2): 203-234.

Rosina, A. and Fraboni, R. (2004). Is marriage losing its centrality in Italy? Demographic Research 11(6): 149-172.

Sabbadini, L.L. (1997). Le convivenze "more uxorio". In: Barbagli, M. and Saraceno, C. (eds.). Lo stato delle famiglie in Italia. Bologna: Il Mulino: 86-94 (Prismi).

Schröder, C. (2006). Cohabitation in Italy: Do parents matter? GENUS LXII(3-4): 5385 .

Silverman, D. (2001). What is qualitative research? In: Silverman. D. (ed.). Interpreting qualitative data: methods for analysing talk, text and interaction. London: Sage Publications: 25-42.

Silverstein, M. and Bengtson, V.L. (1997). Intergenerational solidarity and the structure of adult child-parent relationships in American families. The American Journal of Sociology 103(2): 429-460.

Smith, T.E. (1988). Parental control techniques: relative frequencies and relationships with situational factors. Journal of Family Issues 9(2): 155-176. 
Schröder: The influence of parents on cohabitation in Italy

Weinstein, M. and Thornton, A. (1989). Mother-child relations and adolescent sexual attitudes and behavior. Demography 26(4): 563-577.

Weitzman, L. (1984). Sex-role socialization: A focus on women, In: Freeman, J. (ed.). Women: A Feminist Perspective. Palo Alto, CA: Mayfield Publishing: 157-327. 